\title{
Impacto do turismo em um destino a partir da perspectiva da economia convencional e ecológica
}

\author{
Diomira Maria Cicci Pinto Faria'
}

\section{Resumo}

O objetivo deste estudo é explorar o impacto da atividade turística, sua sustentabilidade na região da Costa do Descobrimento, na Bahia, utilizando as ferramentas da análise econômica convencional e da economia ecológica. Os impactos são mensurados através de indicadores que buscam apresentar além dos impactos da dimensão econômica do fenômeno do turismo, impactos sociais, ambientais e territoriais, que revelem também os retornos à natureza dos resíduos da atividade. Como indicador visual, de conjunto dos resultados obtidos, é apresentada a "Bússola da Sustentabilidade".

Palavras-chave: turismo, economia ecológica, economia convencional, sustentabilidade.

\begin{abstract}
This article presents the economic impact of the tourism, its capacity of human development in an area of Brazil, using the tools of the conventional economic analysis and of the ecological economy. The use of the method of analysis of the ecological economy is justified once the complex structure of the activity of the tourism. A comparison among the two analysis methodologies was an interesting exercise and developing of the studies manifests the importance of incorporating other dimensions besides the economic one in the analysis of tourist projects. So for a better understanding of the current situation and also for the perspective of the economic growth in the future, the chrematistic indicators are not only enough. The ecological economy can help us to understand and to act from the complex interrelations among the several dimensions of the phenomenon of the tourism.
\end{abstract}

Keywords: tourism, ecological economy, conventional economic analysis. sustenainability indicators.

\section{Introdução}

O impacto da atividade turística em destinos é usualmente demonstrado a partir de gráficos com curvas ascendentes que demonstram o crescimento dos empregos gerados e da renda. Do primeiro critério, emprego gerado, às vezes se encontram detalhes como a participação feminina, a sazonalidade, a escolaridade média, Do segundo critério, renda, encontram-se

\footnotetext{
${ }^{1}$ Doutoranda em Eocomia pela Universidade de Alicante, Espanha. E-mail: diomira@ uol.com.br . Endereço: Av. Cristiano Machado 1682/701 Belo Horizonte-MG. CEP: 31 170-800.
} 
geralmente informações referentes a rendimentos, sua evolução, diferença de remuneração entre regiões. Abordagens envolvendo conjuntamente diferentes dimensões do fenômeno turístico são raras. O objetivo deste artigo é oferecer aos leitores uma análise dos impactos da atividade turística a partir de uma ótica multidisciplinar, utilizando uma diversidade de indicadores, cuidadosamente elegidos para demonstrar diferentes impactos da atividade turística na área objeto de análise.

O destino selecionado foi a Costa do Descobrimento, formada pelos municípios de Porto Seguro, Santa Cruz Cabrália e Belmonte, no estado da Bahia. O período de análise compreende os anos de 1991 a 2002. Inicialmente explorando os impactos econômicos da atividade turística, ampliou-se a análise para outras dimensões como a social, ambiental e territorial, seguindo a diretriz da economia ecológica, na tentativa de constituir um campo de estudo interdisciplinar focando a sustentabilidade.

O estudo evolui da apresentação individual do resultado de cada indicador para um visão conjunta, a partir da construção da bússula da sustentabilidade. O resultado revela que os impactos vistos unicamente pela ótica econômica são positivos, mas ao contemplar as outras dimensões, se percebe um desgaste do território que merece cuidados para garantir a sustentabilidade do destino.

O restante do artigo está organizado da seguinte forma. Na próxima seção faz-se uma breve apresentação da economia ecológica. Para tanto, descreve-se a visão básica de mundo, os objetivos, realizando uma comparação entre a economia ecológica e a economia ambiental neoclássica, aqui denominada de convencional. A seção 2 demonstra o vínculo economia ecológica e turismo. A seção 3 apresenta informações sobre o destino, os indicadores selecionados e a construção da bússola da sustentabilidade. A seção 4 oferece algumas conclusões.

\section{Economia ECOLóGICA}

A economia ecológica (EE) é um campo de estudo que abrange as inter-relações entre os sistemas econômico e ecológico. Segundo Martinez Allier², a economia ecológica não é uma disciplina nova, mas sim um novo campo de estudo interdisciplinar que centra sua atenção na sustentabilidade.

A economia ecológica incorpora as tentativas da economia convencional em dar valores monetários a externalidades futuras, incertas, irreversíveis, mas vai além, ao discutir também como se fixam às normas ambientais e como pode ser avaliado fisicamente a insustentabilidade da economia ${ }^{3}$.

Entretanto, difere da economia convencional em termos da amplitude de sua percepção do meio ambiente, como da importância que confere a interação meio ambiente e economia. Assume uma visão mais ampla em termos de espaço, tempo e as partes do sistema a serem objeto de estudo ${ }^{4}$.

\footnotetext{
${ }^{2}$ Martínez, A. (1999); Pg.131.

${ }^{3}$ Martinez, A. (1999); Pg. 129.

${ }^{4}$ Constanza, R. (1994); Pg.113. 
Apresenta-se uma breve comparação entre as linhas de pensamento da economia convencional e ecológica, a partir de alguns fundamentos básicos ${ }^{5}$ :

i) Visão Básica do Mundo: a economia convencional considera os consumidores humanos individuais como as figuras centrais do sistema. Seus gostos e preferências são a força motriz do sistema econômico. Os recursos são ilimitados devido ao progresso tecnológico e a infinita capacidade de substituição dos fatores produtivos. Por outro lado, a EE possui um enfoque holístico. Da ecologia, utiliza a constatação de que os recursos são limitados e os seres humanos são apenas uma espécie dentre as existentes. Mas, atribui maior importância à espécie humana e suas evolução social, cultural, econômica e biológica. Não acredita ser possível uma substituição infinita dos fatores;

ii) Objetivo geral: na economia convencional, do indivíduo e das empresas, o interesse maior é a busca da maximização da utilidade ou do lucro. O meio ambiente significa um fator de produção, a ser utilizado de maneira eficiente, ou seja, ganhar o máximo com o menor custo. Com esta perspectiva, a visão predominante é a de curto prazo. A economia ecológica centra sua atenção na sustentabilidade, em uma visão de longo prazo, em uma harmonia entre os tempos econômicos (regido pelo ritmo acelerado da circulação de capital e taxa de juro) e ecológico (controlado pelo ritmo da natureza) ${ }^{6}$;

iii) Conceito de evolução: na ecologia é um processo de mudança dentro de sistemas complexos através da seleção de elementos transmissíveis, que podem ser biológicos ou culturais. A evolução implica em um sistema de não equilíbrio dinâmico e em adaptação, em lugar de um sistema de equilíbrio estático, em geral utilizado pela economia convencional. A evolução não significa caminhar em uma só direção (crescimento ou progresso). A EE utiliza o conceito de evolução no âmbito de mudanças biológicas e culturais. A evolução biológica é lenta comparada com a evolução cultural;

iv) Objetivos macroeconômicos: O pensamento da economia convencional considera que todo comportamento macro é a soma de comportamentos micro. Na ecologia, o objetivo é a sobrevivência das espécies, enquanto na EE é a sustentabilidade do sistema econômico-ecológico combinado, pois a EE percebe que a busca por um objetivo micro, pode prejudicar ou até anular um objetivo macro. Por isto, concordam com o ditado: pensar global, atuar local;

v) Progresso técnico: o otimismo com a capacidade da tecnologia para solucionar todas as limitações do crescimento econômico contínuo, no que se refere à utilização de recursos, é a visão da economia convencional. Por outro lado, a EE se assenta na prudência ética. Una vez que é grande o nível de incerteza, será irracional estar seguro que a técnica é capaz de remover todas as limitações de recursos. O que a ecologia vem observando é que os recursos são limitados em todos os ecossistemas naturais que existem e que não incluem os seres humanos. Caso a tecnologia não seja capaz de oferecer os recursos necessários, uma perda de capital natural pode significar mudanças irreversíveis. Por isto a necessidade de preservar e manter o capital natural, objetivando a sustentabilidade.

\section{Economia Ecológica e Turismo}

\footnotetext{
${ }^{5}$ Os pontos apresentados estão baseados no artigo de Robert Costanza, 1994.

${ }^{6}$ Martinez, A. (1999); Página 117. 
Segundo Tisdell ${ }^{7}$, a natureza econômica do turismo tem um paralelo com os campos de estudo da ecologia, da economia ambiental e do desenvolvimento econômico. Todas são multidisciplinares, procuram sempre novos e diferentes métodos para analisar os fenômenos, em geral oferecem respostas parciais às perguntas, mas, ao mesmo tempo, produzem excitantes idéias e sugestões à cerca de temas universais da atualidade. Uma destas excitantes idéias resultou na análise do turismo pela ótica da economia ecológica.

Cabe inicialmente definir o que é turismo. Turismo é um fenômeno social de natureza espacial ${ }^{8}$, ou seja, um contingente de pessoas que se movimenta de um lugar de residência habitual para outro onde irá realizar a experiência turística e ali permanecer por um período de tempo. A partir desta definição verifica-se a importância do território, do local onde é realizada a experiência turística, do destino.

Também é importante enfatizar que o turismo não é um setor da economia. Um setor produtivo se define pelo lado da oferta, assim, por exemplo, o setor de calçados se define como tal pelo produto oferecido: sapatos. O turismo é um tipo de demanda que afeta a diversos setores produtivos ${ }^{9}$, como transporte, hotelaria, alimentos e bebidas, comercio, artesanato, entretenimento, entre outros.

A dimensão econômica do turismo é fácil de ser percebida: os empregos gerados, os setores envolvidos, a demanda e a oferta turística, o gasto do turista, são aspectos com terminologia amplamente conhecida pelos atores da atividade turística, que são mensurados e divulgados por diferentes instituições públicas e privadas. Em geral é medida através de ferramentas da economia convencional, que leva em conta elementos visíveis nos mercados formais ou atributos físicos dos setores envolvidos. Os recursos nãotransacionados nos mercados são em geral, esquecidos. Não obstante, para o turismo, estes recursos não-transacionados ou não valorados em mercados formais são significativos, como também são seus impactos. Estes recursos não transacionados referem-se ao solo, ao clima, a paisagem, ou seja, ao meio ambiente.

As variáveis mais importantes no que diz respeito às relações entre turismo e meio ambiente, de acordo com Furió (1996), são as seguintes: i) as pautas de localização no espaço; ii) as características das edificações e iii) a infra-estrutura de acesso. Além de cada uma contribuir de forma significativa à definição dos recursos turísticos naturais, "também contribuem para determinar os aspectos quantitativos ou qualitativos de seu uso e, portanto, definem a natureza, sentido e intensidade dos efeitos meio-ambientais do turismo" ${ }^{10}$.

Podemos fazer um resumo, dizendo que as condições naturais como o clima, o sol, a vegetação, são as matérias-primas do turismo, as quais necessitam de mudanças, de transformações, que utilizam a tecnologia disponível, para permitir seu uso aos clientes, à demanda, que irá consumir estas "matérias-primas transformadas".

\footnotetext{
${ }^{7}$ Tisdell, C. (2001); Pág. 3.

${ }^{8}$ Palomeque, F. (2003). Pág.3

${ }^{9}$ Hidalgo, M. (1996). Pg. 162.

${ }^{10}$ Furió, E. (1996); Página 144. 
Ressalta-se que a infra-estrutura também potencializa os atrativos turísticos naturais ${ }^{11}$. Esta transformação inicia seu processo com a implantação de infra-estrutura, seja viária, sanitária, aeroportuária, etc.

Desta maneira, os fatores causais das mudanças do meio ambiente devido ao turismo são basicamente dois: i) a implantação da infra-estrutura e dos equipamentos e ii) o consumo dos turistas.

Do ponto de vista do "consumo" do turista há dois aspectos em relevo: i) o uso mesmo dos atrativos naturais e ii) os retornos à natureza e a contaminação.

Quanto ao primeiro aspecto, o "consumo" do turista, pode ser verificado através da degradação de uma trilha, da alteração da paisagem, da redução da fauna em determinados locais, e os estudos e dimensionamento de capacidade de carga de atrativos turísticos indicam a preocupação com este aspecto.

Quanto ao retorno à natureza e a contaminação, aspectos menos percebidos, podem ser comprovados através de: i)sobre-exploração e contaminação das praias, seja devido ao uso inadequado e abusivo, como também por um planejamento urbano equivocado, permitindo edificações na primeira linha de praia; ii)contaminação visual, a partir de problemas de degradação da paisagem urbana; iii)sobre-exploração dos recursos minerais e a sobreocupação do solo no momento de implantação do espaço turístico; iv)contaminação da água ou a piora de sua qualidade devido a múltiplas causas, entre elas a falta ou inadequadas técnicas para o tratamento dos esgotos; v)os problemas decorrentes dos resíduos sólidos e seu tratamento, sendo o principal problema a contaminação e degradação da qualidade ambiental do entorno dos espaços turísticos; vi)a contaminação atmosférica, seja devido à concentração demográfica e urbana que o uso do espaço turístico requer, seja na etapa de implantação do mesmo; vii)o ruído gerado pela concentração de turistas em um único local; viii)congestionamento de tráfego, devido a concentração de turistas (espacial ou em determinado período do ano) e ix)destruição de ecossistemas, como os manguezais, seja para construção de edificações, seja como destino de águas residuais ou esgoto sanitário ${ }^{12}$.

A partir das considerações acima é que se pretende analisar os impactos advindos da atividade turística em um destino, contemplando não somente a dimensão econômica do turismo, mas incorporando outras dimensões, que demonstrem os aspectos referentes ao consumo turístico e ao retorno a natureza e a contaminação. Desta forma, acredito dar um "valor agregado" ao estudo realizado.

\section{Estudo de caso: a costa do descobrimento - Bahia}

Este capítulo ${ }^{13}$ apresenta um resumo dos impactos produzidos pelas intervenções do Programa de Desenvolvimento do Turismo na região Nordeste do Brasil - Prodetur/NE, na área denominada Costa do Descobrimento - CD, que compreende os municípios de Porto

\footnotetext{
${ }_{11}^{11}$ Para mais detalhe ver Furió, página 119.

${ }^{12}$ Furió, E. (1996); Capítulo 5.

${ }^{13} \mathrm{O}$ estudo utilizado como referência para os resultados apresentados neste capítulo possui a seguinte referência: Faria, Diomira M.C.P. Análisis económico del turismo desde la perspectiva de la economía ambiental y ecológica. Alicante: Escuela Oficial de Turismo de la Universidad de Alicante: 2005. 
Seguro, Santa Cruz Cabrália e Belmonte, caracterizando-se como o segundo pólo turístico do Estado de Bahia ${ }^{14}$.

Nesta região foram gastos pelo Prodetur/NE cerca de US\$ 83 milhões distribuídos em obras de: a) saneamento; b) transporte; c) recuperação do patrimônio histórico e d) preservação ambiental, durante os anos de 1996 até 2000.

A CD apresentava, no ano 2000, uma população de 139.514 habitantes, com uma atividade econômica com forte presença de setores econômicos que suportam a atividade turística. $\mathrm{O}$ setor de hotelaria ${ }^{15}$ sofreu um crescimento de $6 \%$ ao ano, no período de 1974 a 2000 . Neste último ano, a CD possuía 581 estabelecimentos, 12.392 lugares e 35.609 camas.

O fluxo de turistas, no ano de 2001, foi de aproximadamente um milhão, preferencialmente brasilierios $^{16}$, com média de idade de 36 anos. O tempo de permanência médio é de 7,4 dias, com um salário mensal médio de US\$1.099,00 e um gasto médio diário de US\$27,1.

\subsection{Indicadores}

Serão apresentados neste capítulo indicadores que traduzem o impacto da atividade turística considerando as dimensões econômica, social, ambiental e territorial. Pretende-se conhecer ainda se as atividades ali desenvolvidas são sustentáveis em um período de longo prazo.

Sustentabilidade pode ser definida como a quantidade de consumo que pode continuar indefinidamente sem deteriorar os estoques de capital, incluindo os estoques de capital natural ${ }^{17}$. É uma medida que requer aproximações mais amplas considerando dados sociais, ambientais, territoriais e econômicos que permitam uma visão global da atividade em análise.

Uma das formas de quantificá-la é através da construção de indicadores de sustentabilidade.

A aplicação dos indicadores passa por três fases ${ }^{18}$ :

a) Seleção da dimensão e dos indicadores:

Para a formulação de um bom indicador se deve considerar um aspecto essencial do objetivo proposto, que possa refletir fatos e não impressões subjetivas e principalmente basear-se em dados facilmente disponíveis ${ }^{19}$. Foram selecionados onze indicadores de sustentabilidade para a Costa do Descobrimento. A seleção por estes indicadores se justifica pela disponibilidade de informações e pela necessidade de representar as características sociais e ambientais do espaço turístico.

- Econômicos: Contempla medidas relacionadas com a demanda turística, a geração de emprego e renda;

\footnotetext{
${ }^{14}$ O primeiro é a capital do Estado, Salvador. Medição através do número de turistas.

${ }^{15}$ Plano de Desenvolvimento Integrado do Turismo Sustentável na Costa do Descobrimento - 2001, pg 101103.

16 _ páginas 146-147.

${ }^{17}$ Constanza, R. (1994); Pág. 122.

${ }^{18}$ Mateu, J. (2003), Página 5.

${ }^{19}$ El Enfoque del Marco Lógico, Instituto Universitario de Desarollo y Cooperación (1997), Madrid. 
- Social: Inclui medidas de qualidade de vida da população e níveis de pobreza;

- Territorial e Ambiental: pressão humana sobre o território, medidas relacionadas com a incidência do turismo sobre o meio ambiente. Os indicadores englobam vetores ambientais clássicos, como água, energia e resíduos, medidas relacionadas com o território, como os espaços naturais e construídos.

b) Descrição detalhada de cada um dos indicadores e sua metodologia de cálculo. Permite estabelecer a confiança de cada indicador, apresentando:

- Fontes de dados;

- Método de cálculo;

- Diagnóstico ou linha de base de cada indicador que permita tomar decisões sobre sua evolução.

c) Validação do conjunto de indicadores e sua capacidade comunicativa, devendo selecionar os mais indicados para uma determinada cidade, região ou destino.

\subsubsection{Indicador Econômico - Economia Convencional}

Serão apresentados neste capítulo três indicadores que traduzem a dimensão econômica da atividade turística.

\section{i) Fluxo de Turistas e Receitas}

Verifica-se no Quadro 2 um incremento no fluxo anual de turistas entre o período de 19932000, com reduzidas quedas verificadas nos anos de 1995 e 2001. Por outro lado, as receitas não se comportam da mesma forma, crescendo até o ano de 1998, reduzindo em 19993 2001, recuperando um pouco no ano 2000, embora não alcancem o valor de 1998. Estes resultados revelam uma queda do gasto turístico que pode significar a mudança do segmento de mercado que visita o destino ou um "canibalismo" dos setores ali presentes, principalmente o hoteleiro, quanto a redução de tarifas devido a uma expressiva oferta. Selecionou-se como indicador apenas o número de turistas por possuir maior facilidade de obtenção.

\section{Quadro 2}

\section{Número de Turistas e Receitas}

\begin{tabular}{|c|c|c|}
\hline Ano & Turistas & Receitas (US\$ 1000) \\
\hline 1993 & 567.970 & 110.100 \\
\hline 1994 & 622.890 & 141.730 \\
\hline 1995 & 621.260 & 204.400 \\
\hline 1996 & 753.240 & 234.920 \\
\hline 1997 & 823.730 & 253.190 \\
\hline 1998 & 938.260 & 262.650 \\
\hline 1999 & 1.009 .230 & 229.550 \\
\hline 2000 & 1.037 .450 & 231.300 \\
\hline 2001 & 992.610 & 214.600 \\
\hline
\end{tabular}

Fonte: Bahiatursa, Out/2002.

Indicador: Número de Turistas na Costa do Descobrimento.

Medição: Verificação do Número de Turistas no período de 1993 a 2001. 
Resultado: Alto crescimento do número de turistas no período.

\section{ii) Geração de Emprego ${ }^{20}$}

Para identificar a possibilidade de geração de empregos provenientes de ações em infraestrutura turística na $\mathrm{CD}$, foram utilizadas as informações do Ministério do Trabalho.

O número de pessoas empregadas, nos anos de 1991 e 2001, apresentou um crescimento significativo no setor de serviços. O município de Belmonte não apresentava nenhum emprego neste setor, aumentando para 60 o número de empregados no ano de 2001. Em Porto Seguro e Santa Cruz de Cabrália, o setor de serviços cresceu 17,5\% e 13,5\% ao ano, respectivamente. A participação do setor serviços se revela importante no crescimento geral de empregos no período analisado (18,5\%), como mostra o quadro 1 do Anexo.

Indicador: Empregos por Setor Econômico na Costa do Descobrimento.

Medição: Verificação do Número de Empregados no Setor de Serviços.

Resultado: Importante crescimento do número de empregados.

\section{iii) Renda Mensal do Chefe da Família}

Verificou-se que em todas as faixas de renda houve uma evolução no número de chefes de família. Há um crescimento maior nas faixas intermediária e alta. Entretanto, se pode observar também que a categoria "sem rendimentos" apresentou uma elevação significativa do ano de 1991 a 2000. A expressiva concentração dos chefes de família nos níveis mais baixos da escala salarial se mantém, o que indica que há muito que fazer para alterar a distribuição de renda regional. O IBGE disponibiliza a distribuição de renda mensal dos chefes de família através da quantidade de salários mínimos.

Indicador: Renda do Chefe da Família

Medição: Verificação da Renda do Chefe da Família nos anos de 1991 e 2000.

Resultado: Apesar de uma melhoria na distribuição de renda, com crescimento nos intervalos de maior rendimento, continua uma concentração muito grande nos extratos de baixa renda.

\subsubsection{Indicador Social}

Selecionaram-se dois indicadores para a dimensão social.

\section{iv) Índice de Desenvolvimento Humano (IDH)}

As condições de vida de uma população podem ser medidas e avaliadas por meio de diversas ferramentas. Para esta análise foi utilizado o índice social, elaborado pela Fundação João Pinheiro e PNUD (Programa das Nações Unidas para o Desenvolvimento), denominado de IDH, como mostra o quadro 2 do Anexo.

O Índice de Desenvolvimento Humano (IDH) mede a situação da CD em três dimensões: esperança de vida ao nascer, nível educacional e nível de renda. Verificou-se um incremento do IDH para os três municípios, com ênfase para a educação, elevando o IDH de 0,493 para 0,618 em Belmonte, de 0,590 para 0,699 em Porto Seguro e de 0,560 para

\footnotetext{
${ }^{20}$ Baseado em informações do Plano de Desenvolvimento Integrado do Turismo Sustentável na Costa do Descobrimento - 2001 
0,688 em Santa Cruz de Cabrália, segundo mostra o quadro correspondente. Para efeito de comparação, o IDH do Brasil foi de 0,696, em 1991, passando para 0,766 no ano 2000.

Indicador: Índice de Desenvolvimento Humano.

Medição: Verificação do IDH nos anos de 1991 e 2001.

Resultado: Crescimento do IDH, com ênfase no nível educacional, principal contribuinte para o resultado obtido.

\section{v) Estimativa de Famílias Indigentes}

O desenvolvimento do turismo na região da $\mathrm{CD}$, associado a crise do setor agrícola regional21, foram fatores importantes na decisão de famílias que viviam da agropecuária, em migrar para o litoral, na esperança de obter oportunidade de emprego.

Segundo dados do Censo Demográfico de 1980, do IBGE22, a população dos municípios de Porto Seguro, Santa Cruz de Cabrália e Belmonte totalizavam 44,5 mil habitantes naquele ano, enquanto em 1991 alcançou aproximadamente 63 mil pessoas. Em 1996, o IBGE registrava uma população de 102 mil pessoas, com um incremento de quase $132 \%$, no período.

A partir dos dados do IBGE se pode constatar o incremento do número de famílias indigentes na Costa do Descobrimento, que cresceu 60\% no período 1991 e 2002, conforme mostra o quadro a continuação.

Quadro 3 Estimativa de Famílias Indigentes

\begin{tabular}{|l|r|r|}
\hline \multicolumn{3}{|c|}{ Estimativa de Famílias Indigentes $^{*}$} \\
\hline \multicolumn{3}{|c|}{ Municípios da Costa do Descobrimento } \\
\cline { 2 - 3 } \multicolumn{2}{|c|}{ Municípios } & \multicolumn{2}{|c|}{ Famílias Indigentes } \\
\hline Belmonte & 2.989 & \multicolumn{1}{c|}{$\mathbf{2 0 0 0}$} \\
\hline Porto Seguro & 3.069 & 5.217 \\
\hline Santa Cruz de Cabrália & 678 & 1.884 \\
\hline
\end{tabular}

Fonte: IBGE - Instituto Brasileiro de Geografia e Estatística

* Famílias cuja renda corresponde, no máximo, ao valor de aquisição da cesta básica de alimentos, atendendo aos requerimentos nutricionais recomendados pela FAO/OMS/ONU, ou seja, famílias com renda mensal até 1 salário mínimo

Indicador: Estimativa de Famílias Indigentes na Costa do Descobrimento.

Medição: Verificação do Número de Famílias Indigentes - Instituto Brasileiro de Geografia e Estatística - anos de 1991 e 2000.

Resultado: Alto crescimento do número de famílias indigentes, crescimento de $6 \%$ ao ano na Costa do Descobrimento, resultando em um aumento significativo de $60 \%$ no período de 1991 a 2000.

4.1.3. Indicador Territorial e Ambiental

\footnotetext{
${ }^{21}$ As lavouras de cacau do sul da Bahia, durante os anos de 80 e 90 , foram castigadas com a disseminação da praga "vassoura de bruxa", que reduziu drasticamente a produção local.

${ }^{22}$ IBGE - Instituto Brasileiro de Geografia e Estatística. 


\section{vi) Capacidade de Suporte dos Atrativos Naturais ${ }^{23}$}

A capacidade de suporte, entendida como o número máximo de visitantes por unidade de área que um atrativo pode suportar antes que ocorram alterações no meio físico e sóciocultural, foi adotado ao turismo na década de 60 e aplicado na gestão de atividade de lazer ao ar livre. $\mathrm{Na}$ década seguinte, se transformou em uma variável importante no planejamento turístico.

O Plano de Desenvolvimento Integrado do Turismo Sustentável na CD apresenta os resultados estimados para a Capacidade de Suporte Real - CSR, os quais foram estimados considerando: i)o espaço físico disponível para cada visitante $\left(\mathrm{m}^{2}\right)$ varia conforme o tipo de turismo desejado. Por exemplo, em Caraíva predomina o ecoturismo, assim se definiu $35 \mathrm{~m}^{2}$ de praia por pessoa. Já na costa norte de Porto Seguro (desde a praia até a Ponta do Mutá) ocorre o turismo de massa, por tanto, se estabeleceu $6 \mathrm{~m}^{2}$ por pessoa; ii) as características da praia: se plana ou com declividade; iii) a fragilidade do solo; iv) a maré média, alguns pontos apresentam uma grande variação de área conforme a maré e v) o tempo de permanência do visitante, considerando-se um dia de 12 horas de luminosidade média (no verão a luminosidade é de cerca de 14 hs/dia e no inverno de 10 horas/dia) com uma rotatividade de 2,5 visitantes / dia, ou seja estima-se que cada visitante permaneça cerca de 4:50 horas por dia na praia. Verifica-se que o valor mais baixo é $6 \mathrm{~m}^{2} /$ pessoa nas praias, cujo valor é considerado baixo para o uso de praia por turistas ${ }^{24}$.

Os quadros 3 e 4 no Anexo mostram a freqüência de turistas durante o ano de 2001, revelando a pressão turística existente durante os meses de alta estação (janeiro e julho), duplicando o número de turistas com relação aos meses de baixa estação. Este fato gera pontos de estrangulamento com respeito à infra-estrutura implantada: abastecimento de água potável, esgoto sanitário, coleta e destino de resíduos sólidos.

Somente nos meses de alta estação a CD recebe quase 800 mil turistas, valor superior à capacidade de suporte dos atrativos naturais ali existentes, sendo este de aproximadamente $250.000^{25}$ pessoas. $\mathrm{O}$ número de pessoas nos meses de alta estação é 3,2 vezes maior que a capacidade de suporte dos atrativos naturais da CD.

Indicador: Capacidade de suporte dos atrativos naturais

Medição: Número de turista mês/ capacidade de suporte

Resultado: O número de pessoas nos meses de alta estação é 3,2 vezes maior que a capacidade de suporte.

\section{vii) Uso do Solo}

A pressão exercida pelo processo de urbanização é o efeito mais importante na utilização do território. O quadro 5 no Anexo mostra a evolução da utilização do território na CD. No ano de 1980, a área total da CD possuía 302 mil hectares de superfície dedicada a atividades agropecuárias e em 1995-96 esta área reduziu para 203 mil, uma diminuição de

\footnotetext{
23 Informações retiradas do Plano de Desenvolvimento Integrado do Turismo Sustentável da Costa do Descobrimento - 2001. Para conhecer as críticas a este indicador ver Tisdell, C. ( 2001).

${ }^{24}$ Mateu, Jaume. “Auditorías Ambientales en Destinos Turísitcos” pag 8

${ }^{25}$ Para ser exato a CD recebe 791.111 turistas, para uma capacidade de suporte das praias de 246.318 pessoas.
} 
$33 \%$. Este fato é preocupante, verificando-se uma redução da área verde ao redor do destino, impermeabilizando áreas com a implantação de infra-estrutura e, conseqüentemente, aumento do volume de resíduos que retornam a natureza. O meio ambiente se deteriorou pelo processo de produção econômica, no caso o turismo.

Indicador: Utilização de área para atividade agropecuária.

Medição: Verificação de área (ha) utilizada na atividade agropecuária na CD nos anos de 1980 e 1995-1996.

Resultado: Houve uma diminuição da área destinada à agropecuária (ha) na $\mathrm{CD}$ de $33 \%$, em 16 anos.

\section{viii) Espaços Protegidos}

Com o desenvolvimento do turismo na região da CD, desde 1970, o principal vetor de degradação ambiental tem sido os desmatamentos, as "queimadas", a pressão urbana em áreas que deveriam ser recuperadas e preservadas como os manguezais e as jazidas exploradas para obtenção de material para construção civil.

Para compensar esta degradação e também fazendo parte de um movimento nacional, foram criadas Áreas de Proteção Ambiental - APA's, pertencentes ao Sistema Nacional de Unidades de Conservação - SNUC. As APA's estão inseridas na categoria de manejo sustentável, com a característica de respeitar o uso do solo de acordo com o estabelecido no Plano de Manejo, sem alterar o regime de propriedade ${ }^{26}$.

No quadro 6 do Anexo se pode visualizar a evolução das áreas protegidas na CD, desde 1960 até a década de 90 . O quadro revela que os parques, na década de 60, possuíam 22.500 há de área protegida, passando para 35.782 há, na década de 90 . As Reservas Particulares do Patrimônio Natural aparecem somente a partir da década de 90, com 6.069 ha, o mesmo acontecendo com as APA's, com 65.069 ha. O incremento de área de preservação ambiental auxilia sobremaneira na sustentabilidade do destino.

Indicador: Espaços protegidos.

Medição: Verificação de área (ha) de espaços protegidos nas décadas de 60, 70, 80 e 90.

Resultado: Houve um crescimento importante de áreas protegidas na $\mathrm{CD}$, representadas por parques, reservas particulares e APA's.

\section{ix) Infra-estrutura Social: Rede Pública de Água e Esgoto Sanitário}

Entende-se infra-estrutura social como o conjunto de medidas sanitárias aplicadas especialmente na melhoria das condições de saúde de uma região.

A infra-estrutura social foi a que sofreu maior pressão de demanda nas últimas décadas, devido ao crescimento da população e ao aumento da população flutuante, principalmente durante a alta estação turística. Ressalta-se que a CD necessita dimensionar os sistemas de saneamento para os picos de demanda, que apresentam um consumo bem superior do que aquele exigido no decorrer do ano.

\section{Serviço de Água Potável}

\footnotetext{
${ }^{26}$ Governo do Estado da Bahia. Secretaria de Cultura e Turismo. Superintendência de Desenvolvimento do Turismo. Plano de Manejo: Área de Proteção Ambiental (Marimbus - Iraquara). Salvador: 1998. 
De acordo com dados do Censo Demográfico do IBGE, em 1991, dos domicílios particulares permanentes, $56 \%$ não eram conectados a rede pública de água, o que demonstra que o sistema de abastecimento de água não atendia parte significativa da população residente, quando se iniciaram grandes investimentos públicos na ampliação deste serviço ${ }^{27}$.

Quadro 12 - Evolução do Número de Abastecimento de Água

\begin{tabular}{|l|r|r|r|}
\hline \multicolumn{4}{|c|}{ Evolução do Número de Abastecimentos de Água } \\
\hline \multicolumn{1}{|c|}{ Município } & \multicolumn{1}{c|}{1980} & \multicolumn{1}{c|}{1990} & \multicolumn{1}{c|}{1999} \\
\hline Belmonte & 808 & 1.252 & 2.427 \\
\hline Porto Seguro & 1.141 & 2.310 & 3.209 \\
\hline Santa Cruz de Cabrália & 232 & 567 & 1.480 \\
\hline Total & 2.181 & 4.129 & 7.116 \\
\hline
\end{tabular}

Fonte: Plano de Desenvolvimento Integrado do Turismo

Sustentável na Costa do Descobrimento - 2001

Com um investimento de US\$ 14,4 milhões, chega-se ao final da década de 1990 com uma ampla rede de abastecimento de água, beneficiando as localidades de Porto Seguro, Santa Cruz Cabrália, Arraial d'Ajuda, Coroa Vermelha, Trancoso e Belmonte, abarcando desta forma quase todas as comunidades da $\mathrm{CD}$, resultando na melhoria da qualidade de vida da população.

Atualmente, a região da CD atende cerca de $63,5 \%$ da população residente. Desta forma, apesar de todos os investimentos realizados, são perceptíveis dois tipos de problemas com relação ao abastecimento de água:

- a necessidade de complementação do sistema de abastecimento de água para a população residente que passou a ocupar novos lotes e

- apesar da existência da rede pública, muitos usuários continuam a utilizar água proveniente dos poços artesianos, uma vez que assim procedendo não há necessidade de realizar despesas mensais pagando a conta de água.

\section{Serviço de Esgoto Sanitário}

Nas décadas de 1970 e 1980, as soluções coletivas para a coleta do esgoto sanitário eram praticamente inexistentes, com parte das águas servidas sendo destinadas ao oceano, nos mangues e nos rios da região ${ }^{28}$.

Esta situação perdurou até a década de 90 . Neste momento, o meio ambiente local começava a dar sinais de impactos sofridos durante anos seguidos, com a deterioração de lençóis freáticos, de rios, manguezais, da qualidade das praias, comprometendo o ecossistema.

\footnotetext{
${ }^{27}$ PDITS - Plano de Desenvolvimento Integrado do Turismo Sustentável na CD - 2001 pag 16

${ }^{28}$ PDITS - Plano de Desenvolvimento Integrado do Turismo Sustentável na CD - 2001. 
De acordo com o IBGE, no inicio da década de 1990, 56,23\% dos domicílios da região possuíam alguma alternativa para o destino das águas servidas, na sua maioria poços sépticos.

Com o objetivo de melhorar a qualidade ambiental, foram realizados investimentos da ordem de US\$ 26 milhões para implantar sistemas de esgoto sanitário ${ }^{29}$ em Arraial D’Ajuda, Belmonte, Coroa Vermelha, Porto Seguro (parte), S.C de Cabrália e Trancoso ${ }^{30}$.

As obras executadas têm a capacidade de atender $90 \%$ da população residente e $100 \%$ da flutuante, nas áreas urbanas da região ${ }^{31}$.

Indicador: Percentual de Abastecimento de Água e Esgoto na CD.

Medição: Verificação do número de conexões domiciliares nas décadas de 80 e 90.

Resultado: Incremento significativo do nível de atendimento dos serviços de água potável e esgoto sanitário na $\mathrm{CD}$, embora sejam veiculados problemas nos meses de alta estação. Houve uma melhora na qualidade de vida da população.

\section{x) Coleta e Destino Final de Resíduos Sólidos}

Na década de 90, pouco foi investido na CD com respeito aos serviços de coleta e destino adequado de resíduos sólidos. No ano de 2000 foram realizados investimentos públicos, como a construção do aterro sanitário de Porto Seguro.

Com base no número de domić́lios servidos pelo serviço de coleta de lixo, em 1991, ou seja, de $45,6 \%^{32}$ e em uma pesquisa realizada em 1996, indicando que $87,8 \%$ da população investigada já contava com este serviço, se pode inferir que os investimentos alocados em resíduos sólidos na $\mathrm{CD}$ foram direcionados para a coleta. $\mathrm{O}$ problema mais grave que se verificou na época deste trabalho foi o destino adequado dos resíduos coletados.

Indicador: Coleta e destino final dos Residuos Sólidos.

Medição: Dados secundários para a coleta e verificação in loco do destino final dos Resíduos Sólidos.

Resultado: Houve uma elevação significativa da população atendida por coleta de lixo nos anos de 1991 e 1996, mas nos meses de alta estação há queixas de ineficiência dos serviços. O aterro sanitário implantado no ano de 2000 não se mostra suficiente para ser o destino final dos resíduos sólidos dos três municípios constantes da CD. São os retornos dos resíduos ao meio ambiente, cujo manejo, na época do estudo, não era feita de forma adequada.

\section{xi) Produção de Resíduos Sólidos}

De acordo com a visita realizada na CD no ano de 2003, são coletados 200 toneladas /dia de lixo na alta estação e 70 toneladas /dia na baixa estação ${ }^{33}$, o que corresponde a 1,17 $\mathrm{kg} / \mathrm{hab} /$ dia em Porto Seguro. Número este considerado aceitável para destinos de litoral $^{34}$.

\footnotetext{
${ }^{29}$ Não somente redes, mas também estações de tratamento de esgotos.

${ }^{30}$ PDITS - Plano de Desenvolvimento Integrado do Turismo Sustentável na CD - 2001 Pg 18.

${ }^{31}$ De acordo com dados do projeto executivo.

${ }^{32}$ PDITS - Plano de Desenvolvimento Integrado do Turismo Sustentável na CD - 2001, pg.19.

${ }^{33}$ Visita realizada em setembro de 2003 na Secretaria de Infra-estrutura e Obras de Porto Seguro. 
Indicador: Volume de Resíduos Sólidos em kg/hab/dia.

Medição: Verificação do volume de resíduos sólidos gerados por habitante nos meses de alta e baixa estação.

Resultado: O volume de resíduos sólidos gerados por habitante apresenta uma média aceitável.

\subsubsection{Bússola da Sustentabilidade}

A bússula da sustentabilidade é um indicador visual cuja finalidade é apresentar, em um único instrumento de comunicação, a bússula no caso, a situação de sustentabilidade do destino analisado. Cada indicador possui um espaço na bússula e recebe uma graduação de cor, sendo a melhor situação o verde musgo e a pior o vermelho. Todos os indicadores têm o mesmo peso e a seleção das cores está atrelada ao resultado apresentado por cada indicador.

Em uma forma circular, a bússola contém os onze indicadores escolhidos e seus respectivos resultados, revelando quais têm mais ou menos importância na sustentabilidade do destino analisado.

\section{Bússula de Sustentabilidade do Turismo}

\begin{tabular}{|l|}
$\square 1$ - Comportamento da Demanda \\
$\square 2$ - Estimativa de Famílias Indigentes \\
$\square 3$ - ndicador Trabalhista \\
$\square 4$ - IDH \\
$\square 5$ - Receita do Chefe \\
$\square 6$ - Capacidade de Suporte \\
$\square 7$ - Intensidade do uso do Solo \\
$\square 8$ - Espaços Protegidos \\
$\square 9-$ Conexões de Água e Rede de esgoto \\
$\square 10$ - Residuos Sólidos \\
$\square 11$ - Produção de Residuos Sólidos
\end{tabular}

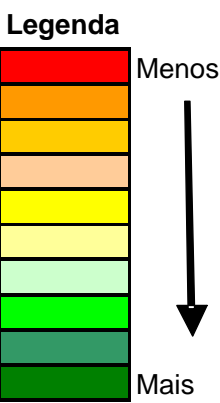

Sustentabilidade

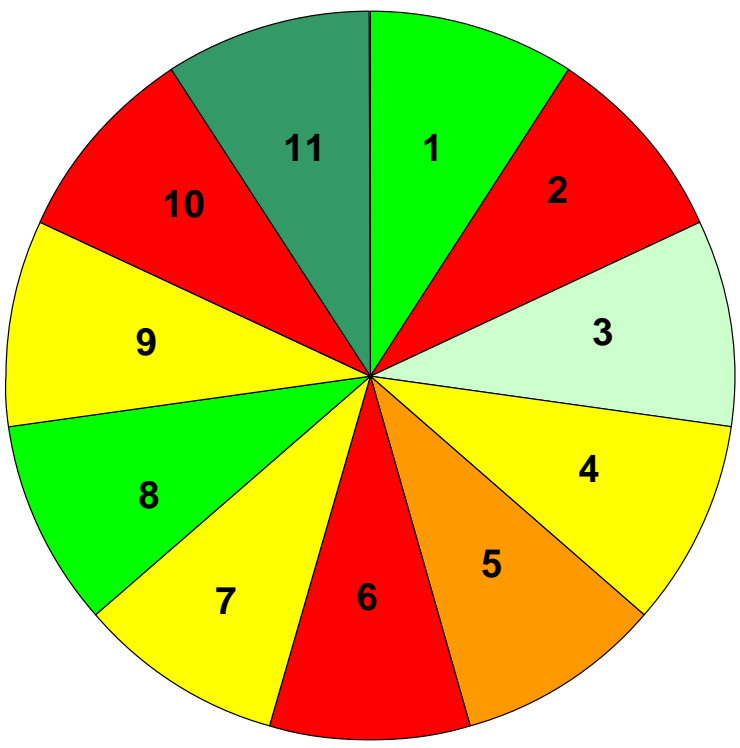

De imediato a cor vermelha de três indicadores salta a vista, demonstrando a necessidade de intervenção urgente, pois os impactos negativos estão comprometendo a

\footnotetext{
${ }^{34}$ De acordo com Mateu, Jaume. "Auditorías Ambientales en Destinos Turísitcos”, a media de 1,5 $\mathrm{Kg} / \mathrm{hab} /$ día de lixo é considerada aceitável. O cálculo utilizado foi : $(200.000 * 30 * 4+70.000 * 30 * 8) / 95.665$ habitantes em Porto Seguro em 2000 ( IBGE). 
sustentabilidade e, conseqüentemente, a continuidade do destino como atrativo turístico. Estes indicadores são referentes ao número de famílias indigentes, capacidade de suporte e o retorno dos resíduos para o meio ambiente (especificamente resíduos sólidos), indicando uma situação crítica de sustentabilidade. Os indicadores de cor amarela ou alaranjada merecem atenção dos administradores locais, ficando em segunda prioridade. Os de cor verde revelam uma situação de sustentabilidade, apoiando o processo de continuidade da atividade turística.

\section{Conclusão}

Através da leitura dos capítulos anteriores se verifica uma complementação entre as duas linhas de pensamento, economia convencional e ecológica.

Ao verificar somente os indicadores econômicos convencionais, o impacto positivo dos investimentos na infra-estrutura turística na Costa do Descobrimento é incontestável.

Mas, a utilização apenas destes indicadores corresponde a uma análise parcial de todo o processo ocorrido neste território. Qual é a perspectiva de continuidade da atividade turística neste local?

A reflexão para responder a esta pergunta passa pela análise do ponto de vista ecológico, quando os indicadores biofísicos são considerados, mostrando que, entre outros fatores, já existe uma pressão demográfica forte e que o crescimento do número de turistas não deve ser incentivado. Há necessidade urgente de investimentos no tocante ao retorno de resíduos a natureza, fonte da contaminação e poluição ambiental.

Para um diagnóstico da situação atual e também para a construção de cenários futuros de desenvolvimento e continuidade da atividade turística somente os indicadores econômicos convencionais não são suficientes.

As recomendações são: i) estabelecer uma mescla de indicadores, apresentando além de indicadores econômicos, aqueles afetos a temas sociais, ambientais e territoriais que permitam diagnosticar, monitorar e dar seguimento aos impactos das atividades econômicas; ii) a partir dos resultados obtidos, listar as prioridades considerando também o retorno dos resíduos ao meio ambiente e iii) traçar uma estratégia de intervenção no território a partir das prioridades e utilizar a bússula como um instrumento de monitoramento.

A qualidade de um destino turístico e sua continuidade como atrativo será possível contemplando além das vantagens econômicas as restrições ambientais e o ciclo biológico do meio ambiente, olhando, a longo prazo, a sustentabilidade do próprio destino e negócio turístico.

A economia ecológica torna possível este ambiente de análise, fazendo com que a economia possa atuar a partir das inter-relações complexas entre as várias dimensões do fenômeno do turismo, ou seja, social, econômica, ambiental e territorial.

\section{Bibliografia}


ARBACHE, Jorge Saba. O mercado de trabalho na atividade turística econômica do turismo no Brasil. Brasília: Editora Universidade de Brasília, 2001.

BAHIATURSA - Instituição oficial do turismo no Estado da Bahia. O desempenho do turismo Baiano: 1991-2001. Salvador: 2002.

CONSTANZA, Robert. "Economia Ecológica - uma agenda de pesquisa". In: Valorando a natureza - análise econômica para o desenvolvimento sustentável. Rio de Janeiro: Campus, 1994.

COOPER, C.; FLETCHER, J.; WANHILL, S.; GILBERT, D.; SHEPARHED, R. Turismo: princípios e prática. São Paulo: Artmed, 2001.

COOPER, C. e ARCHER, B. "The positive and negative impacts of tourism". In: The economics of tourism - volume II. Cheltenham, UK: An Elgar Reference Collection, 2000.

FARIA, Diomira Maria C.P. Análisis económico del turismo desde la perspectiva de la economía ambiental y ecológica. Alicante: Escuela Oficial de Turismo de la Universidad de Alicante: 2005.

FURIÓ, Elies B. Economía, turismo y medio ambiente. Valencia: Tirant lo Blanch, 1996.

HIDALGO, Moisés, M. "Aspectos macroeconómicos del turismo". In: Introducción a la Economía del Turismo en España. Madrid: Civitas, 1996.

INSTITUTO UNIVERSITARIO DE DESARROLLO Y COOPERACIÓN. El Enfoque del Marco Lógico. Madrid: 1997.

MARTINEZ-ALIER, J. Introducción a la Economía Ecológica. Madrid: Rubes Editorial, 1999.

MATEU, Jaume i L. Auditorias ambientales en destinos turísticos. Documento de Trabalho. Alicante: Escuela Oficial de Turismo de la Universidad de Alicante, 2003.

MINISTERIO DE TURISMO Y COMERCIO, SECRETARIA GENERAL DE TURISMO. Turismo y medio ambiente: la sostenibilidad como referencia. Madrid: 1994.

MUELLER, Charles C. Os economistas e as relações entre o sistema econômico e o meio ambiente. Brasília: Editora da Universidade de Brasília, 2007.

PALOMEQUE, Francisco L. El turismo en el desarrollo local y regional: aportaciones conceptuales. Documento de Trabalho. Alicante: Escuela Oficial de Turismo de la Universidad de Alicante, 2003.

GOVERNO DO ESTADO DA BAHIA, RUSCHMANN CONSULTORES. Plano de Desenvolvimento Integrado do Turismo Sustentável na Costa do Descobrimento. Salvador: 2001.

GOVERNO DO ESTADO DA BAHIA, SUPERINTENDENCIA DE ESTUDOS ECONÔMICOS E SOCIAIS. Celulose e Turismo: Extremo Sul da Bahia. Salvador: 1995.

TISDEL, Clem e Wen, Jie. "Why Care is needed in applying indicators of the sustainability of tourism". In: Tourism economics, the environment and development: analysis and policy. Cheltenham, UK: Edward Elgar, 2001. 


\section{Anexos}

\section{Quadro 1}

\begin{tabular}{|c|c|c|c|c|c|c|}
\hline \multicolumn{7}{|c|}{ Empregados por Setor Econômico na Costa do Descobrimento } \\
\hline \multirow{2}{*}{ Setor Econômico } & \multicolumn{2}{|c|}{ Belmonte } & \multicolumn{2}{|c|}{ Porto Seguro } & \multicolumn{2}{|c|}{ Santa Cruz de Cabrália } \\
\hline & 1991 & 2001 & 1991 & 2001 & 1991 & 2001 \\
\hline Extrativa Mineral & - & - & - & - & - & 10 \\
\hline Indústria de Transformação & - & 36 & 213 & 248 & 16 & 142 \\
\hline Serviços industriais de utilidade pública & - & - & - & 19 & - & - \\
\hline Construção Civil & - & 229 & 74 & 452 & - & 5 \\
\hline Comércio & - & 90 & 300 & 1.636 & 64 & 271 \\
\hline Serviços & - & 60 & 1.344 & 5.741 & 91 & 284 \\
\hline Administração Pública & - & 267 & - & 733 & - & 289 \\
\hline $\begin{array}{l}\text { Agropecuária, Extrativismo vegetal, } \\
\text { caça e pesca }\end{array}$ & - & 459 & 153 & 467 & 28 & 523 \\
\hline Outros/lgnorado & - & - & 294 & - & 11 & - \\
\hline Total & - & 1.141 & 2.378 & 9.296 & 210 & 1.524 \\
\hline \multicolumn{7}{|c|}{ Total $1991=2.588$} \\
\hline \multicolumn{7}{|c|}{ Total $2001=11.961$} \\
\hline
\end{tabular}

Quadro 2

\begin{tabular}{|c|c|c|}
\hline \multicolumn{3}{|c|}{ Indice de Desenvolvimento Humano - Municipal (IDH) } \\
\hline \multicolumn{3}{|c|}{ Belmonte } \\
\hline Município & 1991 & 2000 \\
\hline IDH M- Longevidade & 0,524 & 0,586 \\
\hline IDH -M Renda & 0,492 & 0,564 \\
\hline IDH-M - Educação & 0,472 & 0,705 \\
\hline $\mathrm{IDH}-\mathrm{M}$ & 0,493 & 0,618 \\
\hline \multicolumn{3}{|c|}{ Porto Seguro } \\
\hline Município & 1991 & 2000 \\
\hline IDH M- Longevidade & 0,627 & 0,662 \\
\hline IDH -M Renda & 0,563 & 0,651 \\
\hline IDH-M - Educação & 0,581 & 0,783 \\
\hline $\mathrm{IDH}-\mathrm{M}$ & 0,590 & 0,699 \\
\hline \multicolumn{3}{|c|}{ Santa Cruz de Cabrália } \\
\hline Município & 1991 & 2000 \\
\hline IDH M- Longevidade & 0,625 & 0,692 \\
\hline IDH -M Renda & 0,533 & 0,625 \\
\hline IDH-M - Educação & 0,523 & 0,748 \\
\hline $\mathrm{IDH}-\mathrm{M}$ & 0,560 & 0,688 \\
\hline
\end{tabular}

Fonte: Atals de Desenvolvimento Humano - Fundação João

Pinheiro e PNUD (Programa das Nações Unidas para o 


\section{Quadro 3}

\section{Renda Mensal do Chefe do Domicílio}

\begin{tabular}{|c|c|c|c|c|c|c|c|c|}
\hline \multicolumn{9}{|c|}{ Renda Média Mensal do Chefe do Domícílio } \\
\hline \multicolumn{3}{|c|}{ Belmonte } & \multicolumn{3}{|c|}{$\begin{array}{c}\text { Porto Seguro } \\
\end{array}$} & \multicolumn{3}{|c|}{ Santa Cruz de Cabrália } \\
\hline Classe de Rendimento & 1991 & 2000 & Classe de Rendimento & 1991 & 2000 & Classe de Rendimento & 1991 & 2000 \\
\hline Até $1 / 4$ & 82 & 102 & Até $1 / 4$ & 95 & 53 & Até $1 / 4$ & 11 & 22 \\
\hline Mais de $1 / 4$ a $1 / 2$ & 746 & 316 & Mais de $1 / 4$ a $1 / 2$ & 1.610 & 314 & Mais de $1 / 4$ a $1 / 2$ & 196 & 104 \\
\hline Mais de $3 / 4$ a 1 & 796 & 2.260 & Mais de $3 / 4$ a 1 & 537 & 4.816 & Mais de $3 / 4$ a 1 & 180 & 1.285 \\
\hline Mais de 1 a $11 / 4$ & 598 & 153 & Mais de 1 a $11 / 4$ & 836 & 692 & Mais de 1 a $11 / 4$ & 167 & 145 \\
\hline Mais de 1 1/4 a $11 / 2$ & 273 & 327 & Mais de $11 / 4$ a $11 / 2$ & 422 & 2.000 & Mais de 1 1/4 a $11 / 2$ & 82 & 527 \\
\hline Mais de $11 / 2$ a 2 & 249 & 483 & Mais de $11 / 2$ a 2 & 451 & 3.618 & Mais de $11 / 2$ a 2 & 84 & 780 \\
\hline Mais de 3 a 5 & 106 & 239 & Mais de 3 a 5 & 339 & 2.520 & Mais de 3 a 5 & 62 & 506 \\
\hline Mais de 5 a 10 & 87 & 169 & Mais de 5 a 10 & 353 & 1.940 & Mais de 5 a 10 & 68 & 370 \\
\hline Mais de 10 a 15 & 18 & 38 & Mais de 10 a 15 & 111 & 501 & Mais de 10 a 15 & 22 & 97 \\
\hline Mais de 15 a 20 & 9 & 14 & Mais de 15 a 20 & 32 & 356 & Mais de 15 a 20 & 4 & 58 \\
\hline Mais de 20 a 30 & 15 & 9 & Mais de 20 a 30 & 50 & 148 & Mais de 20 a 30 & 4 & 23 \\
\hline Mais de 30 & - & 19 & Mais de 30 & - & 242 & Mais de 30 & - & 34 \\
\hline Sem rendimentos & 403 & 172 & Sem rendimentos & 964 & 3.472 & Sem rendimentos & 115 & 1.028 \\
\hline Total & 4.968 & 5.091 & Total & 7.222 & 23.905 & Total & 1.378 & 5.758 \\
\hline
\end{tabular}

Fonte: IBGE - Instituto Brasileiro de Geografia e Estatística 
Quadro 4

\begin{tabular}{|c|c|c|}
\hline \multicolumn{3}{|c|}{ Capacidade de Suporte/Dia nos Atrativos Naturais } \\
\hline Localidade/Praia & $\begin{array}{l}\text { Capacidade Física de Suporte/dia } \\
\text { (em no de pessoas) }\end{array}$ & $\begin{array}{l}\text { m2 por } \\
\text { pessoas }\end{array}$ \\
\hline \multicolumn{3}{|c|}{ Belmonte } \\
\hline $\begin{array}{l}\text { Barra do Rio Preto até a Praia do Mar } \\
\text { Moreno }\end{array}$ & 64.722 & 20 \\
\hline $\begin{array}{l}\text { Praia do Mar Moreno até a Foz do Rio } \\
\text { Jequitinhonha }\end{array}$ & 24.292 & \\
\hline $\begin{array}{l}\text { Foz do Rio Jequitinhonha até a Divisa } \\
\text { Caravelas }\end{array}$ & 38.712 & 20 \\
\hline Total do Município & 127.726 & 15,33 ( média) \\
\hline \multicolumn{3}{|c|}{ Porto Seguro } \\
\hline Praia até a Ponta do Mutá & 37.500 & \\
\hline Arraial D'Ajuda & 12.000 & 10 \\
\hline Vila de Trancoso & 9.000 & 14 \\
\hline Caraíva & 1.250 & 35 \\
\hline Total do Município & 59.750 & 16,25 (média) \\
\hline \multicolumn{3}{|c|}{ Santa Cruz de Cabrália } \\
\hline Praia até a Ponta do Mutá & 15.250 & 8,5 \\
\hline Ponta de Santo André & 562 & 20 \\
\hline $\begin{array}{l}\text { Ponta do Santo André até Fazenda } \\
\text { Amendoeira }\end{array}$ & 4.745 & 20 \\
\hline $\begin{array}{l}\text { Fazenda Amendoeira até a Barra do } \\
\text { Santo Antônio }\end{array}$ & 11.440 & 20 \\
\hline Barra do Santo Antônio até Rio Guaiú & 19.500 & 20 \\
\hline Rio Guaiú até Barra do Rio Preto & 7.345 & 20 \\
\hline Total do Município & 58.842 & 18,08 (média) \\
\hline Total da Costa do Descobrimento & 246.318 & \\
\hline
\end{tabular}

Fonte: Plano de Desenvolvimento Integrado do Turismo Sustentável na Costa do Descobrimento 2001

Quadro 5

\begin{tabular}{|l|r|}
\hline \multicolumn{2}{|c|}{ Pressão Turística na Costa do Descobrimento } \\
\hline \multicolumn{1}{|c|}{ Meses } & \multicolumn{1}{|c|}{ Turistas $^{*}$} \\
\hline Janeiro & 578.692 \\
Fevereiro & 29.778 \\
Março & 7.941 \\
Abril & 2.978 \\
Maio & 1.985 \\
Junho & 9.926 \\
Julho & 212.419 \\
Agosto & 5.956 \\
Setembro & 4.963 \\
Outubro & 6.948 \\
Novembro & 993 \\
Dezembro & 130.032 \\
Total & 992.610 \\
\hline
\end{tabular}

Fonte: Bahiatursa,2001 - Organismo Oficial de Estatística de Turismo do Estado da Bahia 


\section{Quadro 6}

\begin{tabular}{|c|c|c|c|c|c|c|c|c|}
\hline \multicolumn{9}{|c|}{ Utilização do Solo } \\
\hline \multicolumn{3}{|c|}{ Belmonte } & \multicolumn{3}{|c|}{ Porto Seguro } & \multicolumn{3}{|c|}{ Santa Cruz de Cabrália } \\
\hline Classificação (HA) & 1980 & $\overline{1995-1996}$ & Classificação (HA) & 1980 & 1995-1996 & Classificação (HA) & 1980 & $1995-1996$ \\
\hline Área Total do Município (2001) & & .680 & Área Total do Município (2001) & & .660 & Área Total do Município (2001) & & 0.650 \\
\hline Área Total da Agropecuária* & 107.481 & 94.388 & Área Total da Agropecuária* & 85.435 & 74.703 & Área Total da Agropecuária* & 109.528 & 34.451 \\
\hline Lavouras Permanentes & 17.106 & 12.693 & Lavouras Permanentes & 8.203 & 7.245 & Lavouras Permanentes & 2.989 & 2.244 \\
\hline Lavouras Temporárias & 2.341 & 664 & Lavouras Temporárias & 6.424 & 1.007 & Lavouras Temporárias & 3.102 & 1.007 \\
\hline Lavouras em Descanso & 2.167 & 1.067 & Lavouras em Descanso & 2.511 & 1.696 & Lavouras em Descanso & 5.194 & 145 \\
\hline Pastagens Naturais & 14.739 & 14.464 & Pastagens Naturais & 14.774 & 20.410 & \begin{tabular}{|l} 
Pastagens Naturais \\
\end{tabular} & 34.303 & 6.528 \\
\hline Pastagens Plantadas & 5.205 & 26.133 & Pastagens Plantadas & 12.416 & 25.840 & Pastagens Plantadas & 17.443 & 8.020 \\
\hline Matas e Florestas Naturais & 41.593 & 27.671 & Matas e Florestas Naturais & 26.643 & 10.386 & Matas e Florestas Naturais & 27.512 & 12.606 \\
\hline Matas e Florestas Plantadas & 232 & 154 & Matas e Florestas Plantadas & 65 & 567 & Matas e Florestas Plantadas & 23 & 818 \\
\hline Produção Não Utilizada & 10.977 & 5.722 & Produção Não Utilizada & 10.074 & 5.837 & Produção Não Utilizada & 14.321 & 1.763 \\
\hline Terras Impróprias para Cultivo & 13.121 & 5.820 & Terras Impróprias para Cultivo & 4.325 & 1.715 & Terras Impróprias para Cultivo & 4.641 & 1.320 \\
\hline Outras Áreas & 94.199 & 107.292 & Outras Areas & 156.225 & 166.957 & Outras Areas & 46.122 & 121.129 \\
\hline
\end{tabular}

Fonte: * SEl - Superintendência de Estudos Econômicos e Sociais da Bahia - www.sei.ba.gov.br

IBGE - Instituto Brasilerio de Geografia e Estatística - Setor Agropecuário 


\section{Quadro 7}

\begin{tabular}{|c|c|c|c|c|c|c|c|c|}
\hline \multicolumn{9}{|c|}{ Unidades de Conservação da Costa do Descobrimento } \\
\hline Categorias & Unidades & \multicolumn{4}{|c|}{ Ano de Criação / Área (HA) } & Municípios & Descrição & Situação Atual \\
\hline \multirow{4}{*}{ Parques } & $\begin{array}{l}\text { Parque Nacional de } \\
\text { Monte Pascoal }\end{array}$ & 22.500 & 22.500 & 22.500 & 22.500 & Porto Seguro & $\begin{array}{l}\text { Matas de encostas e atlântica, } \\
\text { restingas, mangues e áreas de praia. }\end{array}$ & $\begin{array}{l}\text { Plano de Manejo em 1979. Plano Emergencial em } \\
\text { 1995. Sem equipamentos receptivos. }\end{array}$ \\
\hline & \begin{tabular}{|l|} 
Parque Municipal \\
Marinho do Recife de \\
Fora
\end{tabular} & - & - & - & 1.750 & Porto Seguro & Diversas espécies de vida marinha. & $\begin{array}{l}\text { Não há Plano de manejo. Visitação controlada pela } \\
\text { Prefeitura Municipal, mas enfrentando ainda problemas } \\
\text { com a falta de recursos para gestão da unidade. }\end{array}$ \\
\hline & \begin{tabular}{|l|} 
Parque Municipal \\
Marinho de Coroa \\
Alta
\end{tabular} & - & - & - & - & $\begin{array}{l}\text { Santa Cruz de } \\
\text { Cabrália }\end{array}$ & $\begin{array}{l}\text { Formação mista de corais e bancos de } \\
\text { areia. }\end{array}$ & $\begin{array}{l}\text { Não há Plano de manejo. Visitação controlada pela } \\
\text { Prefeitura Municipal, mas enfrentando ainda problemas } \\
\text { com a falta de recursos para gestão da unidade. }\end{array}$ \\
\hline & $\begin{array}{l}\text { Parque Nacional de } \\
\text { Pau Brasil }\end{array}$ & - & - & - & 11.532 & Porto Seguro & Maior reserva existente de Pau-Brasil. & $\begin{array}{l}\text { Não está aberto a visitação e não possui regularização } \\
\text { fundiária. }\end{array}$ \\
\hline & tal Hectares & 22.500 & 22.500 & 22.500 & 35.782 & & & \\
\hline \multirow{2}{*}{$\begin{array}{c}\text { Reserva } \\
\text { Particular do } \\
\text { Patrimônio } \\
\text { Natural }\end{array}$} & \begin{tabular}{|l} 
Reserva Particular do \\
Patrimônio Natural \\
Estação Veracruz
\end{tabular} & - & - & - & 6.069 & Porto Seguro & Reserva de Mata Atlântica & $\begin{array}{l}\text { Possui Plano de Manejo. Desenvolve atividades de } \\
\text { Educação Ambiental e de Ecoturismo. Quase } 15.000 \\
\text { visitantes em } 1999 .\end{array}$ \\
\hline & \begin{tabular}{|l|} 
Reserva Particular do \\
Patrimônio Natural \\
Fazenda Manona
\end{tabular} & \multicolumn{3}{|c|}{ Em processo de Criação } & - & Porto Seguro & $\begin{array}{l}\text { Ecossistemas de restinga, mata de } \\
\text { transição e mata ciliar. }\end{array}$ & $\begin{array}{l}\text { Não possui Plano de manejo. Desenvolve o turismo } \\
\text { ecológico }\end{array}$ \\
\hline \multicolumn{2}{|c|}{ Total Hectares } & - & - & - & 6.069 & & & \\
\hline \multirow{3}{*}{$\begin{array}{l}\text { Área de } \\
\text { Proteção } \\
\text { Ambiental }\end{array}$} & $\begin{array}{l}\text { APA Caraíva - } \\
\text { Trancoso }\end{array}$ & & - & - & 31.900 & Porto Seguro & $\begin{array}{l}\text { Faixa de } 6 \text { a } 8 \mathrm{Km} \text { na linha costeira } \\
\text { entre Trancoso e Caraíva. }\end{array}$ & Possui Plano de Manejo aprovado pelo CRA. \\
\hline & APA Coroa Vermelha & & - & - & 4.100 & $\begin{array}{l}\text { Santa Cruz de } \\
\text { Cabrália e Porto } \\
\text { Seguro }\end{array}$ & $\begin{array}{l}\text { Faixa de } 1 \mathrm{Km} \text { na linha costeira do } \\
\text { sitío histórico da Coroa Vermelha. }\end{array}$ & Possui Plano de Manejo aprovado pelo CRA. \\
\hline & APA Santo Antônio & & - & - & 23.000 & $\begin{array}{l}\text { Belmonte e Santa } \\
\text { Cruz de Cabrália }\end{array}$ & $\begin{array}{l}\text { Faixa de } 5 \mathrm{Km} \text { na linha costeira entre } \\
\text { Santa Cruz de Cabrália e Belmonte. }\end{array}$ & $\begin{array}{l}\text { Possui Plano de Manejo aprovado pelo CRA. Plano de } \\
\text { Uso Ecoturísitco concluído e em fase de aprovação. }\end{array}$ \\
\hline \multicolumn{2}{|c|}{ Total Hectares } & - & - & - & 65.069 & & & \\
\hline
\end{tabular}

Fonte: Plano de Desenvolvimento Integrado do Turismo Sustentável na Costa do Descobrimento - 2001 